\title{
Clinical effect and safety evaluation of hydromorphone combined with sufentanil in patient-controlled intravenous analgesia for patients with hepatocellular cancer and its effect on serum immune factors
}

\author{
JITONG LIU, YONGSHENG WANG, YIXUN TANG, JIA LUO, YI LONG and SUHONG TAN
}

Department of Anesthesiology, Hunan Provincial People's Hospital, Changsha, Hunan 410005, P.R. China

Received August 1, 2019; Accepted July 16, 2020

DOI: $10.3892 / \mathrm{ol} .2020 .12159$

\begin{abstract}
The present study aimed to explore the clinical efficacy and safety of hydromorphone combined with sufentanil in patient-controlled intravenous analgesia (PCIA) for patients with hepatocellular carcinoma (HCC) and its effect on serum immune factors in serum. Data from 385 patients with HCC, admitted to the Hunan Provincial People's Hospital (Changsha, China) from February 2015 to September 2018, were retrospectively analyzed. Laparoscopic hepatectomy was performed in all patients. A total of 180 patients who received PCIA were treated with sufentanil (control group), and 205 patients who received PCIA were treated with hydromorphone and sufentanil (study group). PCIA was used after hepatocellular cancer operation. In the control group, the analgesic pump was filled with sufentanil $(2 \mu \mathrm{g} / \mathrm{kg})$ and tropisetron $(5 \mathrm{mg})$, whereas in the study group, the analgesic pump was filled with sufentanil $(2 \mu \mathrm{g} / \mathrm{kg})$, tropisetron $(5 \mathrm{mg})$ and hydromorphone $(5 \mathrm{mg})$. Both groups of drugs were diluted into $100 \mathrm{ml}$ with normal saline and the loading dose was $5 \mathrm{ml}$; the continuous dose was $2 \mathrm{ml} / \mathrm{h}$ and the single PCIA amount was $2 \mathrm{ml}$. The visual analogue scale (VAS) and numeric sedation scale (NSS) scores at 12 and $24 \mathrm{~h}$ after operation, as well as and satisfaction score at $24 \mathrm{~h}$ after operation, were recorded. The levels of $\mathrm{CD}^{+}, \mathrm{CD}^{+}$, $\mathrm{CD}^{+}$lymphocytes and NK cells in the peripheral blood of patients were detected by flow cytometry. The postoperative hospitalization time, first flatulence time, first defecation time and first ambulation time, as well as the adverse reactions, were recorded. The results revealed that the satisfaction score of the patients at $24 \mathrm{~h}$ after operation was significantly higher in the study group than that in the control group $(\mathrm{P}<0.05)$. Additionally, there were no serious adverse reactions in either
\end{abstract}

Correspondence to: Dr Jitong Liu, Department of Anesthesiology, Hunan Provincial People's Hospital, 61 Jiefang West Road, Changsha, Hunan 410005, P.R. China

E-mail: josb58@163.com; liujitong008@163.com

Key words: hydromorphone, sufentanil, patient-controlled analgesia, hepatocellular carcinoma group. In conclusion, PCIA with hydromorphone and sufentanil can provide safe and effective analgesia, may improve the levels of immune factors and enhance the recovery ability of the patients.

\section{Introduction}

Hepatocellular carcinoma (HCC) is the fifth most common cancer in men and ninth in women, making HCC the second leading cause of cancer-related deaths worldwide (1). According to global epidemiological statistics, the number of deaths of hepatocellular cancer every year has reached $>700,000$ (2). It has been reported (3) that the mortality rate of hepatocellular cancer has been increasing in many parts of the world. However, the mortality rate has decreased in some Asian countries (3) because of the progress in hepatocellular cancer treatment.

HCC surgical treatment has become the most commonly used and effective method for the treatment of HCC, due to its application and development (4). The severe pain after operation, if not intervened, leads to stress and suppression of the immune function, which have serious effects on the patient prognosis. Thus, effective postoperative analgesia is needed (5). Patient-controlled intravenous analgesia (PCIA) is an intravenous drug-using method for analgesia, which is easy to implement and with a wide range of drugs to use. The advantages are quick onset and wide application. At the same time, PCIA's disadvantage lies in the wide range of drugs, i.e., the analgesic effect of different drugs is quite different. For example, the effect of dizoxacin is good, but the dependence is strong; pethidine works quickly, but the analgesic effect is general (6). Hydromorphone is a semi-synthetic derivative of morphine, which has good analgesic effect; however, at the same time, it has some side effects, such as mental confusion and diarrhea (7). Sufentanil is a powerful opioid that provides long-term central analgesia and has been successfully used in postoperative analgesia after laparoscopic cholecystectomy. However, a study has shown that the analgesic effect of this drug alone on liver operation and other traumatic operations is limited (8). It has been reported that $0.10 \%$ of ropivacaine combined with $15 \mu \mathrm{g} / \mathrm{ml}$ of hydromorphone has good analgesic effect, mild motor block and high safety (9). Considering the 
short analgesia time of ropivacaine (10), it has been shown that dizoxine combined with sufentanil can reduce the inhibitory effect on NK cells and $\mathrm{CD}^{+}$activity, and inhibit the activity of $\mathrm{CD}^{+}$cells (11). In the present study, whether hydromorphone combined with sufentanil could have a similar outcome, and the effect of this combination on pain, while affecting the levels of immune factors, were investigated.

The clinical effect and safety evaluation of hydromorphone combined with sufentanil in PCIA for patients with HCC, as well as their effect on serum immune factors, were compared with those of sufentanil treatment alone, in order to clarify the analgesic effect of hydromorphone and provide reference for the clinical treatment of HCC.

\section{Patients and methods}

General data. Clinical data from 385 patients with HCC (40-60 years of age), treated in the Hunan Provincial People's Hospital (Changsha, China) from February 2015 to September 2018, were retrospectively analyzed. The patients were divided into two groups according to the method of analgesia used. A total of 205 patients received the combination of hydromorphone and sufentanil PCIA (study group), and 180 patients were treated with sufentanil PCIA (control group). The study was approved by the Medical Ethics Committee of Hunan Provincial People's Hospital. All patients and their families were informed by letter or telephone, and signed informed consents were obtained from the patients and/or guardians.

Inclusion criteria: All patients were diagnosed with HCC by pathology and met the diagnostic criteria (12); all patients underwent laparoscopic hepatectomy; no radiotherapy, chemotherapy or related immunotherapy was performed before serum specimen acquisition; patients had complete clinical data.

Exclusion criteria: Patients with abnormal kidney and cardiopulmonary function; pregnant or breast-feeding patients; patients with mental illness or abnormal brain judgment.

Analgesia method. In the control group, the analgesic pump was filled with sufentanil and tropisetron. The details are as follows: $2 \mu \mathrm{g} / \mathrm{kg}$ of sufentanil (SFDA approval no. H20120094; Yichang Renfu Pharmaceuticals Co., Ltd.) and $5 \mathrm{mg}$ of tropisetron (SFDA approval no. H20050535; Qilu Pharmaceutical Co., Ltd.). In the study group, the analgesic pump was filled with hydromorphone, sufentanil and tropisetron. The details are as follows: $5 \mathrm{mg}$ of hydromorphone (SFDA approval no. H20120100; Yichang Renfu Pharmaceuticals Co., Ltd.) and the dosage of sufentanil and tropisetron was the same as that of the control group. The drugs in both groups were diluted into $100 \mathrm{ml}$ with normal saline and the loading dose was $5 \mathrm{ml}$; the continuous dose was $2 \mathrm{ml} / \mathrm{h}$ and the single dose of PCIA was $2 \mathrm{ml}$.

Observation indicators. The general data of the two groups were collected and compared, including sex, age, body mass index (BMI), tumor location, tumor size, alanine aminotransferase (ALT), operative time and others.

The visual analogue scale (VAS) and numeric sedation scale (NSS) scores at 12 and $24 \mathrm{~h}$ after operation were recorded in both groups, as well as the and satisfaction score at $24 \mathrm{~h}$ after operation. VAS system: 0 Point, no pain; 1-2 points, occasionally mild pain; 3-4 points, often mild pain; 5-9 points, obvious pain; 10 points, intolerable pain. NSS system: 1 Point, not quiet, restlessness; 2 points, quiet cooperation; 3 points, lethargy, patient able to follow instructions; 4 points, sleep state, but the patient can be awakened; 5 points, slow respiratory response; 6 points, deep sleep state, the patient can't be called to wake up. Satisfaction score system: 1 Point, unsatisfied; 2 points, basically satisfied; 3 points, satisfied; 4 points, quite satisfied.

Peripheral venous blood $(1.5 \mathrm{ml})$ was collected into an Eppendorf (EP) tube and heparin was used for anticoagulation. Another four EP tubes were used and numbered as 1, 2, 3 and 4 . A total of $150 \mu \mathrm{l}$ of venous blood were added into each EP tube. Tube 1 was filled with antibodies IgG-FITC/IgG-PE (10 $\mu \mathrm{l}$ each); tube 2 was filled with antibodies CD3-FITC/CD4-PE (10 $\mu$ l each); tube 3 was filled with antibodies CD3-FITC/CD8-PE (10 $\mu \mathrm{l}$ each); tube 4 was filled with antibodies CD3-FITC/CD16+56-PE (10 $\mu \mathrm{l}$ each). All tubes were placed in the dark for $20 \mathrm{~min}$. Hemolysin $(2 \mathrm{ml})$ was added, and the tubes were left for $10 \mathrm{~min}$ in the dark. Next, after centrifugation at $1,000 \mathrm{xg}$ for $5 \mathrm{~min}$ at $4^{\circ} \mathrm{C}$, the precipitate was rinsed with PBS. After a second centrifugation at $1,000 \mathrm{x} \mathrm{g}$ for $5 \mathrm{~min}$ at $4^{\circ} \mathrm{C}$, the supernatant was discarded. A total of $3 \mathrm{ml}$ of $1 \%$ paraformaldehyde were added before the detection by FACScan flow cytometer (BD Diagnostics). CD3, CD4, CD8 and $\mathrm{CD} 16+56$ detection kits were purchased from Beckman Coulter, Inc. The analysis software used was FACScan analysis software embedded in FACScan flow cytometer.

In addition, the postoperative hospitalization time, first flatulence time, first defecation time and first ambulation time were recorded, as well as the occurrence of adverse reactions after operation, such as nausea, emesis and diarrhea.

Statistical analysis. SPSS 19.0 software (AsiaAnalytics; formerly SPSS China) was used to statistically analyze the data. Counting data were expressed as $\mathrm{n}(\%)$. The comparison of the rates between the two groups was carried out by $\chi^{2}$ test. Enumeration data were expressed as the mean \pm standard deviation and their comparison between the two groups was carried out by independent samples t-test. Repeated measures ANOVA was used for the comparison of the data at different time-points in the same group, and LSD test was the post hoc test used. $\mathrm{P}<0.05$ was considered to indicate a statistically significant difference.

\section{Results}

General characteristics of the two groups of patients. There were 180 patients in the control group, including 118 males $(65.56 \%)$ and 62 females $(34.46 \%)$ with average age of $51.6 \pm 10.8$ years. In the study group, there were 205 patients, including 132 males (64.39\%) and 73 females (35.61\%) with average age of $52.7 \pm 9.5$ years. There was no significant difference in sex, age, BMI, location of tumor, AST, ALT or other general characteristics between the two groups $(\mathrm{P}>0.05)$, as presented in Table I.

Analysis of pain and sedation index. Intragroup comparisons: VAS and NSS scores at $24 \mathrm{~h}$ after operation were superior to 
Table I. Patient general characteristics.

\begin{tabular}{|c|c|c|c|c|}
\hline Characteristics & Control group $(\mathrm{n}=180)$ & Study group $(n=205)$ & $\chi^{2} /$ t value & P-value \\
\hline $\operatorname{Sex}[\mathrm{n}(\%)]$ & & & 0.057 & 0.810 \\
\hline Male & $118(65.56)$ & $132(64.39)$ & & \\
\hline Female & $62(34.46)$ & $73(35.61)$ & & \\
\hline Age (years) & $51.6 \pm 10.8$ & $52.7 \pm 9.5$ & 1.063 & 0.288 \\
\hline BMI $\left(\mathrm{kg} / \mathrm{m}^{2}\right)$ & $25.1 \pm 3.9$ & $24.9 \pm 4.2$ & 0.552 & 0.518 \\
\hline Tumor size $(\mathrm{cm})$ & $6.4 \pm 2.5$ & $6.6 \pm 3.2$ & 0.677 & 0.499 \\
\hline Tumor location [n (\%)] & & & 0.454 & 0.500 \\
\hline Left & $86(47.8)$ & $105(51.2)$ & & \\
\hline Right & $94(52.2)$ & $100(48.8)$ & & \\
\hline AST (U/l) & $73.5 \pm 40.4$ & $70.7 \pm 46.4$ & 0.989 & 0.323 \\
\hline $\operatorname{ALT}(\mathrm{U} / \mathrm{l})$ & $69.6 \pm 43.6$ & $72.5 \pm 40.6$ & 0.676 & 0.500 \\
\hline $\mathrm{TBiL}(\mu \mathrm{mol} / \mathrm{l})$ & $25.4 \pm 5.6$ & $24.7 \pm 7.3$ & 1.045 & 0.297 \\
\hline Operative time (min) & $176.1 \pm 46.8$ & $181.5 \pm 37.5$ & 1.273 & 0.204 \\
\hline Hilar blocking time (min) & $13.6 \pm 4.3$ & $12.5 \pm 6.8$ & 1.867 & 0.063 \\
\hline Bleeding (ml) & $343.5 \pm 48.2$ & $335.7 \pm 52.3$ & 1.514 & 0.131 \\
\hline Infusion (ml) & $2,320.7 \pm 463.5$ & $2,230.5 \pm 500.8$ & 1.826 & 0.069 \\
\hline $\operatorname{AFP}(\mathrm{ng} / \mathrm{ml})$ & $50.3 \pm 16.8$ & $52.4 \pm 15.6$ & 1.271 & 0.204 \\
\hline $\mathrm{CEA}(\mathrm{ng} / \mathrm{ml})$ & $19.8 \pm 7.6$ & $20.6 \pm 8.9$ & 0.942 & 0.347 \\
\hline
\end{tabular}

Hilar blocking time is the time required to reduce bleeding before intraoperative operation of the liver. BMI, body mass index; AST, aspartate aminotransferase; ALT, alanine aminotransferase; TBiL, total bilirubin; AFP, $\alpha$-fetoprotein; CEA, carcinoembryonic antigen.

those at $12 \mathrm{~h}$ after operation, and the differences were statistically significant $(\mathrm{P}<0.05)$. Intergroup comparisons: VAS and NSS scores in the study group were better than those in the control group at 12 and $24 \mathrm{~h}$ after operation, and the differences were statistically significant $(\mathrm{P}<0.05$; Table II).

Analysis of patient satisfaction. The satisfaction score at $24 \mathrm{~h}$ after operation in the study group was significantly higher than that in the control group $(\mathrm{P}<0.05$; Fig. 1$)$.

Analysis of immune cell levels. Intragroup comparisons: Compared with the levels before anesthesia, the levels of $\mathrm{CD}^{+}$, $\mathrm{CD}^{+}, \mathrm{CD}^{+}$and $\mathrm{NK}$ cells in both groups were significantly decreased at 12 and $24 \mathrm{~h}$ after operation $(\mathrm{P}<0.05)$. Intergroup comparisons: There was no significant difference in the activity of $\mathrm{CD}^{+}, \mathrm{CD}^{+}, \mathrm{CD}^{+}$and $\mathrm{NK}$ cells before anesthesia; however, the levels were significantly higher in the study group compared with those in the control group at 12 and $24 \mathrm{~h}$ after operation (Figs. 2 and 3).

Analysis of postoperative rehabilitation. The postoperative hospitalization time, first flatulence time, first defecation time and first ambulation time were shorter in the study group than those in the control group $(\mathrm{P}<0.05$; Table III).

Analysis of adverse reactions. There was no significant difference in nausea, emesis, diarrhea, dizziness or hear burn between the two groups after operation $(\mathrm{P}>0.05)$. In addition, there was no significant difference in the total adverse reactions $(\mathrm{P}>0.05)$ between the two groups. There were no other serious adverse reaction in either group (Table IV).



Figure 1. Analysis of patient satisfaction. The satisfaction score at $24 \mathrm{~h}$ after operation was significantly higher in the study group than that in the control group. ${ }^{*} \mathrm{P}<0.05$.

\section{Discussion}

HCC pathogenesis is not clear yet, which limits the choices of treatment. Hepatectomy is still the first choice of treatment. The 5-year survival rate of patients with HCC is between 30 and $40 \%$ (13). Postoperative pain after hepatectomy is one of the serious challenges, thus it is necessary for postoperative 
Table II. Analysis of pain and sedation indexes (scores).

\begin{tabular}{|c|c|c|c|c|}
\hline Scoring system & Control group $(n=180)$ & Study group $(\mathrm{n}=205)$ & t value & P-value \\
\hline \multicolumn{5}{|l|}{ VAS } \\
\hline $12 \mathrm{~h}$ after operation & $4.5 \pm 0.6$ & $4.1 \pm 1.6$ & 3.164 & 0.002 \\
\hline $24 \mathrm{~h}$ after operation & $3.6 \pm 0.4^{\mathrm{a}}$ & $2.9 \pm 0.5^{\mathrm{a}}$ & 15.029 & $<0.001$ \\
\hline \multicolumn{5}{|l|}{ NSS } \\
\hline $12 \mathrm{~h}$ after operation & $2.3 \pm 0.5$ & $3.2 \pm 0.6$ & 15.861 & $<0.001$ \\
\hline $24 \mathrm{~h}$ after operation & $2.8 \pm 0.7^{\mathrm{a}}$ & $3.7 \pm 0.5^{\mathrm{a}}$ & 14.641 & $<0.001$ \\
\hline
\end{tabular}

VAS, visual analogue scale; NSS, numeric sedation scale. ${ }^{\mathrm{a}} \mathrm{P}<0.05$, compared with the same group at $12 \mathrm{~h}$ after operation.
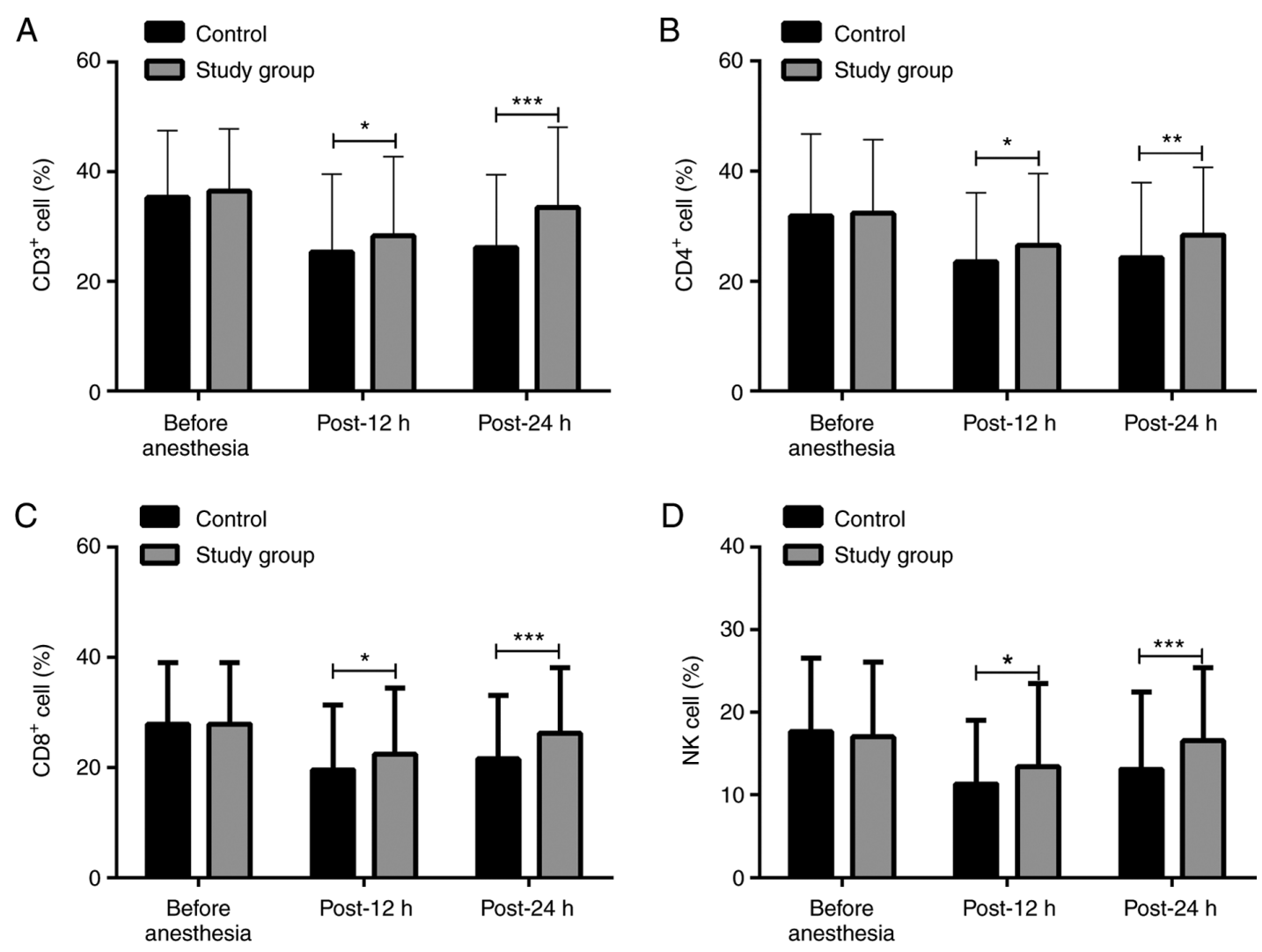

Figure 2. Comparison of the levels of the immune cells in the two groups of patients. The levels of (A) $\mathrm{CD}^{+}$(B) $\mathrm{CD} 4^{+}$(C) $\mathrm{CD} 8^{+}$and (D) NK cells in the two groups of patients at different time-points were detected. $\mathrm{P}<0.05,{ }^{* *} \mathrm{P}<0.01$ and ${ }^{* * * *} \mathrm{P}<0.001$, compared with the control group. Post- $12 \mathrm{~h}, 12 \mathrm{~h}$ after operation; Post-24 h, $24 \mathrm{~h}$ after operation.

PCIA to control the pain of patients, relieve their discomfort and enhance the recovery (14). A study has shown that dexmetomide can effectively maintain the homeostasis of cellular immune function in patients undergoing radical mastectomy, can effectively improve the recovery of patients and reduce inflammation (15). Another study has reported that dexmetomide can effectively reduce the release of inflammatory factors in patients undergoing radical resection of gastric cancer and can reduce the decrease of $\mathrm{CD}^{+}$and $\mathrm{CD}^{+}$cells to improve the impairment of immune function (16). These studies have shown that drug PCIA has a positive effect on the immune function of the body. In the present study, the clinical effect and safety assessment of hydromorphone combined with sufentanil for PCIA in patients with HCC were retrospectively analyzed, and the effect on the patients' immune function was verified by examining the difference of the immune cells in the serum to provide reference for the clinical treatment of postoperative pain in patients with HCC.

A total of 385 patients with HCC were included in the study, and the patients were divided into two groups according to the different methods of drug analgesia that they received. The analysis of the basic data of the two groups showed that there was no significant difference between the two groups. VAS and NSS scores at 12 and $24 \mathrm{~h}$ after operation, as well as the patient satisfaction after $24 \mathrm{~h}$, were significantly different between the two groups, suggesting that the postoperative analgesia effect of the combination of hydromorphone and sufentanil was better than that of the sufentanil analgesia alone. At $12 \mathrm{~h}$ 
Table III. Analysis of postoperative rehabilitation.

\begin{tabular}{|c|c|c|c|c|}
\hline Variables & Control group $(n=180)$ & Study group $(n=205)$ & $\mathrm{t}$ value & P-value \\
\hline Postoperative hospitalization time (days) & $12.5 \pm 1.8$ & $9.7 \pm 2.5$ & 12.456 & $<0.001$ \\
\hline First flatulence time (h) & $55.8 \pm 10.6$ & $47.6 \pm 8.3$ & 8.500 & $<0.001$ \\
\hline First defecation time (h) & $88.6 \pm 11.6$ & $82.4 \pm 9.3$ & 5.815 & $<0.001$ \\
\hline First ambulation time (h) & $4.5 \pm 0.5$ & $3.2 \pm 1.1$ & 14.586 & $<0.001$ \\
\hline
\end{tabular}

Table IV. Analysis of adverse reactions [n (\%)].

\begin{tabular}{|c|c|c|c|c|}
\hline Adverse reactions & Control group $(n=180)$ & Study group $(n=205)$ & $\chi^{2}$ value & P-value \\
\hline Nausea & $7(3.89)$ & $8(3.90)$ & $4.70 \times 10^{-5}$ & 0.995 \\
\hline Vomiting & $7(3.89)$ & $6(2.93)$ & 0.272 & 0.521 \\
\hline Diarrhea & $6(3.33)$ & $8(3.90)$ & 0.089 & 0.766 \\
\hline Dizziness & $8(4.44)$ & $10(4.88)$ & 0.040 & 0.841 \\
\hline Heart burn & $9(5.00)$ & $12(5.85)$ & 0.135 & 0.713 \\
\hline Total adverse reactions & $37(20.56)$ & $44(21.46)$ & 0.048 & 0.827 \\
\hline
\end{tabular}
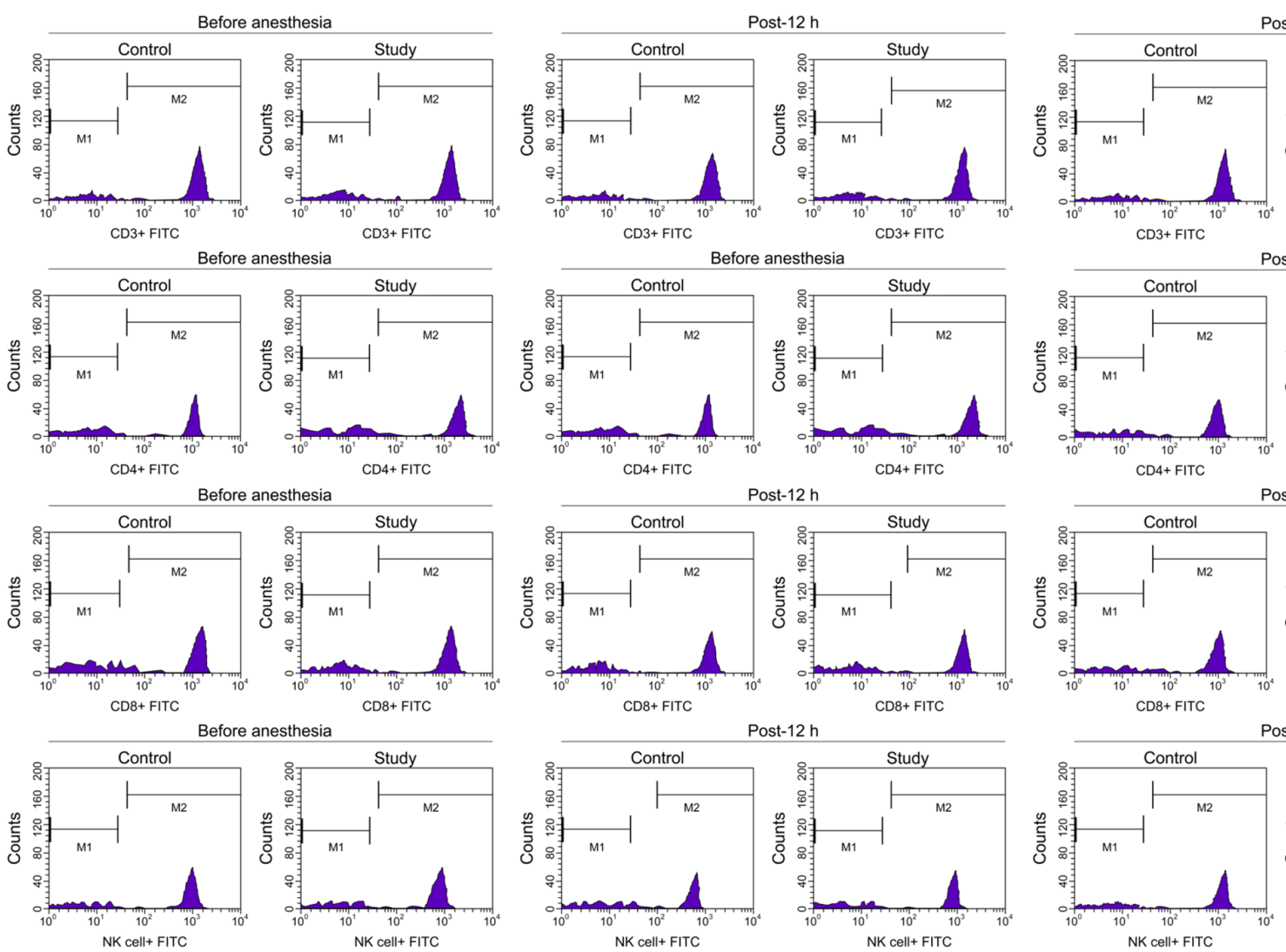

Post-24 h
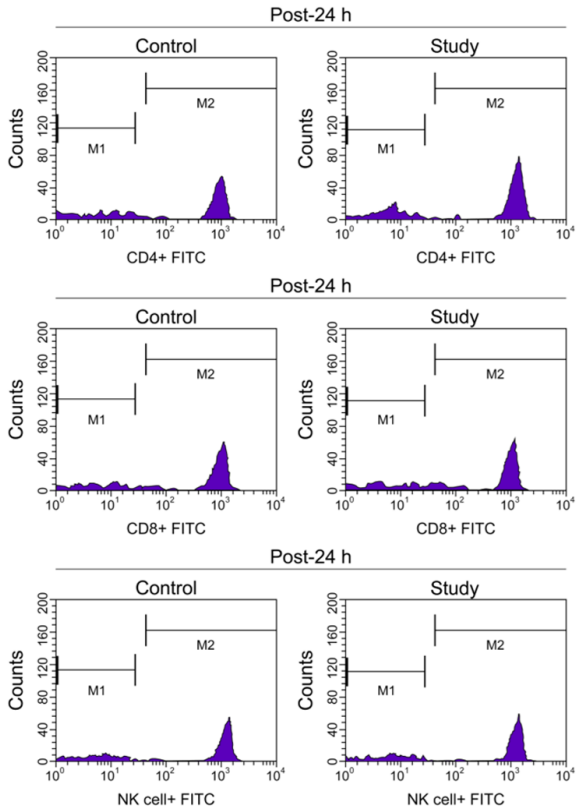

Figure 3. Flow cytometry plots before anesthesia and at 12 and $24 \mathrm{~h}$ after operation. Post-12 h, 12 h after operation; Post-24 h, 24 h after operation.

after operation, the levels of immune factors in the study group were higher than those in the control group, suggesting that the combination of hydromorphone and sufentanil had a significant effect on improving the immune level of the body. In addition, there was no significant difference in postoperative adverse reactions between the two groups, suggesting that the PCIA assisting role of hydromorphone is desirable. A previous study has shown that there was no significant difference in analgesic effect and adverse reactions between hydromorphone alone and sufentanil alone (17). Another study (18) has shown that the administration of dexmetiomide combined with sufentanil for postoperative analgesia in patients with partial laryngectomy 
can reduce the dosage of sufentanil and improve the analgesic effect, reduce the cough frequency of patients and improve the sleep quality. However, the rate of adverse reactions was still as high as $37.8 \%$ (18), and the incidence of adverse reactions was $10.73 \%$ in this study.

The abnormal expressions of various pain mediators in vivo will lead to acute pain, and the detection of the level of patient mediators can objectively reflect the subjective pain degree of patients. The effect threshold or stimulation range of the combination of multiple drugs on pain mediators is wider than that of drugs alone, and the effect on nervous system is better than that of drugs alone $(19,20)$. Some studies have shown that sufentanil combined with butorphenol has a stronger analgesic effect than butorphenol alone (21), the combination of dexmedetomidine and sufentanil in the treatment of PCIA after thoracoscopic lobectomy has better analgesic effect and more stable blood flow dynamics than that of sufentanil alone, and can reduce the dose of sufentanil and the adverse reaction (22). These studies have confirmed that the effect of combined drugs is better than that of drugs alone. In addition, it has been reported that the high density of $\mathrm{CD}^{+}$and $\mathrm{CD}^{+} \mathrm{T}$ cells is closely related to the recurrence rate of patients with breast cancer. The higher the activity, the lower the recurrence rate, and the higher the survival rate of the patients (23). Another study showed that the survival time of patients with CD8CT density $>93$ cells $/ \mathrm{mm}^{2}$ was significantly longer than that of patients with CD8CT density $<93$ cells $/ \mathrm{mm}^{2}$ (24). One study demonstrated that the density of $\mathrm{CD}^{+}, \mathrm{CD}^{+}$, and T-lymphocytes can predict the survival rate of advanced colon cancer (25). Another study has shown that the pro-inflammatory tumor micro-environment and infiltrating $\mathrm{T}$ lymphocytes expressing CD8 are related to the improvement of clinical outcomes of various tumor types. For example, bone marrow-derived inhibitory cells and regulatory $\mathrm{T}$ cells seem to play an important role in undermining the immune control of cancer (26). On this basis, we believe that PCIA with better results after operation may reduce the recurrence rate and improve the survival rate, which could be verified in future studies.

Although this study confirmed the effect of the combination of hydromorphone and sufentanil for the PCIA after hepatectomy, there are still some deficiencies. The study did not investigate the PCIA of secondary hepatocellular cancer. This will be the aim of our future research. In addition, there are some limitations due to the retrospective character of the study. Serum pain mediators would be useful in determining the clinical response of patients; however, the serum pain medium data were not collected in this study. Moreover, the lack of a larger sample size may have produced inevitable deviation to the experimental results. These shortcomings will be addressed in our future research.

In conclusion, PCIA with hydromorphone combined with sufentanil can provide safe and effective analgesia, may improve the patients' immune function and enhance the recovery ability of the body, providing future reference for the clinical application of hydromorphone combined with sufentanil PCIA.

\section{Acknowledgements}

Not applicable.

\section{Funding}

The study was financially supported by the Natural Science Foundation of Hunan Province, 'Study of Mechanism of Targeted Temperature Management Induced Neuroprotection after Cardiac Arrest Based on NPD1-Iduna pathway and a potential therapy strategy' project (grant no. 2020JJ4404).

\section{Availability of data and materials}

The datasets used and/or analyzed during the present study are available from the corresponding author on reasonable request.

\section{Authors' contributions}

JLi and YW analyzed and interpreted the patients' data. YT and JLu were responsible for the flow cytometry. YL and ST assisted with statistical analysis. JLi wrote the manuscript. All authors read and approved the final manuscript.

\section{Ethics approval and consent to participate}

The study was approved by the Medical Ethics Committee of Hunan Provincial People's Hospital (Changsha, China). Patients who participated in this study had complete clinical data. Signed written informed consents were obtained from the patients and/or guardians.

\section{Patient consent for publication}

Not applicable.

\section{Competing interests}

The authors declare that they have no competing interests.

\section{References}

1. Ryerson AB, Eheman CR, Altekruse SF, Ward JW, Jemal A, Sherman RL, Henley SJ, Holtzman D, Lake A, Noone AM, et al: Annual report to the nation on the status of cancer, 1975-2012, featuring the increasing incidence of liver cancer. Cancer 122: 1312-1337, 2016.

2. Wang Y, He L, Du Y, Zhu P, Huang G, Luo J, Yan X, Ye B, Li C, Xia P, et al: The long noncoding RNA lncTCF7 promotes self-renewal of human liver cancer stem cells through activation of Wnt signaling. Cell Stem Cell 16: 413-425, 2015.

3. Hu XY, Hou PF, Li TT, Quan HY, Li ML, Lin T, Liu JJ, Bai J and Zheng JN: The roles of Wnt/ $/$-catenin signaling pathway related IncRNAs in cancer. Int J Biol Sci 14: 2003-2011, 2018.

4. Lee MW and Lim HK: Management of sub-centimeter recurrent hepatocellular carcinoma after curative treatment: Current status and future. World J Gastroenterol 24: 5215-5222, 2018.

5. Chen X, Sun Y, Cai R, Wang G, Shu X and Pang W: Long noncoding RNA: Multiple players in gene expression. BMB Rep 51: 280-289, 2018.

6. Zhao X, Sun B, Liu T, Shao B, Sun R, Zhu D, Zhang Y, Gu Q, Dong X, Liu F, et al: Long noncoding RNA n 339260 promotes vasculogenic mimicry and cancer stem cell development in hepatocellular carcinoma. Cancer Sci 109: 3197-3208, 2018.

7. Brogan SE, Winter NB and Okifuji A: Prospective observational study of patient-controlled intrathecal analgesia: Impact on cancer-associated symptoms, breakthrough pain control, and patient satisfaction. Reg Anesth Pain Med 40: 369-375, 2015.

8. Li Z, Wu H, He R, Hu X and Liu S: Oxycodone versus dezocine for postoperative analgesia in patients with cervical cancer treated with radical surgery. J Cancer Res Ther 12 (Suppl 1): S27-S29, 2016. 
9. Lu YY, Huang H, Mao WL, Liu RH, Hu MJ, Shao LX, Hu MP and Li J: A concentration-response observation of hydromorphone combined with ropivacaine in labor analgesia. Zhonghua Yi Xue Za Zhi 97: 3297-3300, 2017 (In Chinese).

10. Bhatia N, Mehta S, Saini V, Ghai B and Kaman L: Comparison of intraperitoneal nebulization of ropivacaine with ropivacaine-fentanyl combination for pain control following laparoscopic cholecystectomy: A randomized, double-blind, placebo-controlled trial. J Laparoendosc Adv Surg Tech A 28: 839-844, 2018.

11. Edwards BK, Noone AM, Mariotto AB, Simard EP, Boscoe FP, Henley SJ, Jemal A, Cho H, Anderson RN, Kohler BA, et al: Annual report to the nation on the status of cancer, 1975-2010, featuring prevalence of comorbidity and impact on survival among persons with lung, colorectal, breast, or prostate cancer. Cancer 120: 1290-1314, 2014.

12. Bray F, Ferlay J, Laversanne M, Brewster DH, Gombe Mbalawa C, Kohler B, Piñeros M, Steliarova-Foucher E, Swaminathan R, Antoni S, et al: Cancer incidence in five continents: Inclusion criteria, highlights from volume $\mathrm{X}$ and the global status of cancer registration. Int J Cancer 137: 2060-2071, 2015.

13. Du H, Le Y, Sun F, Li K and Xu Y: ILF2 directly binds and stabilizes CREB to stimulate malignant phenotypes of liver cancer cells. Anal Cell Pathol (Amst) 2019: 1575031, 2019.

14. Eheman C, Henley SJ, Ballard-Barbash R, Jacobs EJ, Schymura MJ, Noone AM, Pan L, Anderson RN, Fulton JE, Kohler BA, et al: Annual report to the nation on the status of cancer, 1975-2008, featuring cancers associated with excess weight and lack of sufficient physical activity. Cancer 118: 2338-2366, 2012.

15. Yang XH, Bai Q, Lv MM, Fu HG, Dong TL and Zhou Z: Effect of dexmedetomidine on immune function of patients undergoing radical mastectomy: A double blind and placebo control study. Eur Rev Med Pharmacol Sci 21: 1112-1116, 2017

16. Sayed JA, Abd Elshafy SK, Kamel EZ, Fathy Riad MA, Mahmoud AA and Khalaf GS: The impact of caudally administered tramadol on immune response and analgesic efficacy for pediatric patients: A comparative randomized clinical trial. Korean J Pain 31: 206-214, 2018.
17. Dong W, Chen MH, Yang YH, Zhang X, Huang MJ, Yang XJ and Wang HZ: The effect of dexmedetomidine on expressions of inflammatory factors in patients with radical resection of gastric cancer. Eur Rev Med Pharmacol Sci 21: 3510-3515, 2017.

18. Peng Z, Zhang Y, Guo J, Guo X and Feng Z: Patient-controlled intravenous analgesia for advanced cancer patients with pain: A retrospective series study. Pain Res Manag 2018: 7323581, 2018.

19. Jemal A, Simard EP, Dorell C, Noone AM, Markowitz LE, Kohler B, Eheman C, Saraiya M, Bandi P, Saslow D, et al: Annual report to the Nation on the status of cancer, 1975-2009, featuring the burden and trends in human papillomavirus(HPV)-associated cancers and HPV vaccination coverage levels. J Natl Cancer Inst 105: 175-201, 2013.

20. Kim KH: Neurourological application of neurogenesis and inflammation and pain mechanisms of rocuronium bromide. Int Neurourol J 20: 274-275, 2016.

21. Kurozumi S, Matsumoto H, Kurosumi M, Inoue K, Fujii T, Horiguchi J, Shirabe K, Oyama T and Kuwano H: Prognostic significance of tumour-infiltrating lymphocytes for oestrogen receptor-negative breast cancer without lymph node metastasis. Oncol Lett 17: 2647-2656, 2019.

22. Galon J, Mlecnik B, Bindea G, Angell HK, Berger A, Lagorce C, Lugli A, Zlobec I, Hartmann A, Bifulco C, et al: Towards the introduction of the 'Immunoscore' in the classification of malignant tumours. J Pathol 232: 199-209, 2014.

23. Gabrielson A, Wu Y, Wang H, Jiang J, Kallakury B, Gatalica Z, Reddy S, Kleiner D, Fishbein T, Johnson L, et al: Intratumoral CD3 and CD8 T-cell densities associated with relapse-free survival in HCC. Cancer Immunol Res 4: 419-430, 2016.

24. Sun C, Xu J, Song J, Liu C, Wang J, Weng C, Sun H, Wei H, Xiao W, Sun R and Tian Z: The predictive value of centre tumour CD8 ${ }^{+}$ $\mathrm{T}$ cells in patients with hepatocellular carcinoma: Comparison with Immunoscore. Oncotarget 6: 35602-35615, 2015.

25. Kwak Y, Koh J, Kim DW, Kang SB, Kim WH and Lee HS: Immunoscore encompassing $\mathrm{CD}^{+}$and $\mathrm{CD}^{+} \mathrm{T}$ cell densities in distant metastasis is a robust prognostic marker for advanced colorectal cancer. Oncotarget 7: 81778-81790, 2016.

26. Barnes TA and Amir E: HYPE or HOPE: The prognostic value of infiltrating immune cells in cancer. Br J Cancer 117: 451-460, 2017. 